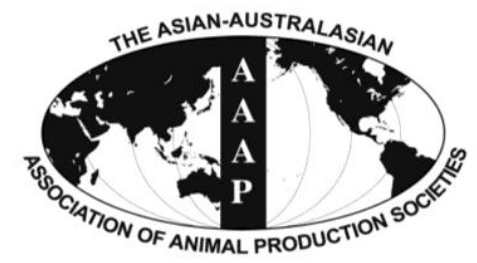

Asian-Aust. J. Anim. Sci.

Vol. 26, No. 3 : 316-322 March 2013

http://dx.doi.org/10.5713/ajas.2012.12469

www.ajas.info

pISSN 1011-2367 elSSN 1976-5517

\title{
Discrimination of Korean Native Chicken Lines Using Fifteen Selected Microsatellite Markers
}

\author{
D. W. Seo, M. R. Hoque, N. R. Choi, H. Sultana, H. B. Park ${ }^{1,2}$, K. N. Heo ${ }^{3}$, B. S. Kang ${ }^{3}$, \\ H. T. Lim ${ }^{1,2}$, S. H. Lee ${ }^{4}$ C. Jo and J. H. Lee* \\ Department of Animal Science and Biotechnology, Chungnam National University, Daejeon 305-764, Korea
}

\begin{abstract}
In order to evaluate the genetic diversity and discrimination among five Korean native chicken lines, a total of 86 individuals were genotyped using 150 microsatellite (MS) markers, and 15 highly polymorphic MS markers were selected. Based on the highest value of the number of alleles, the expected heterozygosity (He) and polymorphic information content (PIC) for the selected markers ranged from 6 to $12,0.466$ to $0.852,0.709$ to 0.882 and 0.648 to 0.865 , respectively. Using these markers, the calculated genetic distance $(F s t)$, the heterozygote deficit among chicken lines (Fit) and the heterozygote deficit within chicken line (Fis) values ranged from 0.0309 to $0.2473,0.0013$ to 0.4513 and -0.1002 to 0.271 , respectively. The expected probability of identity values in random individuals $(\mathrm{PI})$, random half-sib $\left(\mathrm{PI}_{\text {half-sibs }}\right)$ and random sibs $\left(\mathrm{PI}_{\text {sibs }}\right)$ were estimated at $7.98 \times 10^{-29}, 2.88 \times 10^{-20}$ and $1.25 \times 10^{-08}$, respectively, indicating that these markers can be used for traceability systems in Korean native chickens. The unrooted phylogenetic neighbor-joining (NJ) tree was constructed using 15 MS markers that clearly differentiated among the five native chicken lines. Also, the structure was estimated by the individual clustering with the $\mathrm{K}$ value of 5 . The selected $15 \mathrm{MS}$ markers were found to be useful for the conservation, breeding plan, and traceability system in Korean native chickens. (Key Words: Discrimination, Diversity, Microsatellite, Korean Native Chicken, Traceability)
\end{abstract}

\section{INTRODUCTION}

The Korean native chicken has been documented since approximately 2,000 years ago. Due to their poor commercial performance, Korean native chicken breeds almost became extinct. For this reason, Korean native chicken conservation strategies have been launched by the Korean government in 1994. Based on the 2 decades of the conservation project's duration, five native chicken breeds with nine lines have been developed. In Korea, approximately $90 \%$ of chicken meat consumption is based on imported breeds. Recently, the poultry meat production

\footnotetext{
* Corresponding Author: Jun-Heon Lee. Tel: +82-42-821-5779, Fax: +82-42-825-9754, E-mail: junheon@cnu.ac.kr

1 Department of Animal Science, Gyeongsang National University, Jinju 660-701, Korea.

${ }^{2}$ Institute of Agriculture and Life Sciences, Gyeongsang National University, Jinju 660-701, Korea

${ }^{3}$ Poultry Science Division, National Institute of Animal Science, RDA, Cheonan 331-801, Korea.

${ }^{4}$ Hanwoo Experiment Station, National Institute of Animal Science, RDA, Pyeongchang 232-956, Korea.

Submitted Sept. 3, 2012; Accepted Oct. 31, 2012; Revised Nov. 23, 2012
}

has steadily increased, accounting for up to $20 \%$ of the total meat consumption in Korea (MIFAFF, 2009). Nowadays, many Korean consumers have a higher preference for native chicken meat than before, even though they may be 2 to 3 times as expensive as broilers.

Evaluation of genetic diversity for local breeds is becoming more challenging, and large efforts have been concentrated on maintaining minimum number of animals for each native species (FAO, 2007). There are extensive advantages of microsatellite (MS) markers because MS markers are abundant repeats of one to six bases, exhibit codominant inheritance, and are highly polymorphic and dispersed throughout the genome (Cheng and Crittenden, 1994; Kaya and Yildiz, 2008). In the Ark Database, the documented chicken MS markers are 2,483 markers, of which 435 are unmapped (Jacobsson et al., 2004). Until now, MS markers are the most widely used for the improvement of genetic selection management, parentage studies, evolutionary analysis, genetic traceability systems and QTL mapping (Blott et al., 1999; Dalvit et al., 2007; Almasy and Blangero, 2009). Previously, twenty two MS markers were used to assess chicken domestication in 52 populations. The results from identified alleles and the 
amount of genetic variation supported the hypothesis that the red jungle fowl was the ancient progenitor (Hillel et al., 2003). Therefore, MS markers are more suitable for the study of genetic diversity, correlation studies, and for identifying population structure among the chicken populations (Kong et al., 2006; Muchadeyi et al., 2007; Mwacharo et al., 2007; Tadano et al., 2007a; Tadano et al., 2007b; Berthouly et al., 2008; Bodzsar et al., 2009; Ding et al., 2010). On the other hand, the single nucleotide polymorphism (SNP) markers in MC1R gene were not sufficient for the discrimination of these Korean native chicken lines (data has not shown). Also, the phylogenetic relationships between Korean native chicken and other breeds have been investigated using D-loop sequence variations in mtDNA and attempts for discrimination of Korean native chicken lines were performed using mtDNA and LEI0258 marker (Hoque et al., 2009; Hoque et al., 2011).

In our studies, 15 markers have been selected from the 150 MS markers in the Ark database in order to investigate Korean native chicken lines to identify their genetic relationships. Also, these markers were used for the calculation of discrimination probabilities, which can be used for chicken traceability systems. Also, these results can be used in further breeding and conservation strategies for Korean native chicken.

\section{MATERIALS AND METHODS}

\section{Sample collection and DNA extraction}

Five Korean native chicken lines were collected from the National Institute of Animal Science (NIAS) in Korea. These lines were basically classified according to their feather colors, which were white (KNC_W), black (KNC_B), red-brown (KNC_R), yellow-brown (KNC_Y) and gray (KNC_G) lines. A total of 86 individuals were used for DNA extraction from blood samples collected from wing veins in tubes containing EDTA. Samples were stored at $-20^{\circ} \mathrm{C}$ and genomic DNAs were extracted using a manual extraction method (Miller et al., 1988).

\section{PCR amplification and genotyping}

Initially, $150 \mathrm{MS}$ markers were selected from the Ark Database (http://www.thearkdb.org/arkdb/) and were genotyped (Table 1). The primers used for genotyping were labeled with four fluorescence dyes (FAM, NED, VIC, PET) in forward primers. For the discrimination analysis of chicken lines, 15 highly polymorphic microsatellite markers were selected based on the number of alleles, expected heterozygosity (He) and polymorphic information content (PIC) values (Table 2). PCR was performed in an initial denaturation at $95^{\circ} \mathrm{C}$ for $10 \mathrm{~min}$, followed by 35 cycles of
$30 \mathrm{~s}$ at $95^{\circ} \mathrm{C}, 30 \mathrm{~s}$ at $60^{\circ} \mathrm{C}, 30 \mathrm{~s}$ at $72^{\circ} \mathrm{C}$ and a final extension at $72^{\circ} \mathrm{C}$ for $10 \mathrm{~min}$ using My-Genie96 Thermal Cycler (Bioneer, Korea). The PCR products were initially electrophoresed on $4 \%$ agarose gel with ethidium bromide, and DNA bands were visualized under ultraviolet light. For genotyping, the final genotyping reactions were based on 1 $\mu \mathrm{l}$ of $20 \mathrm{X}$ diluted PCR products, $10 \mu \mathrm{l}$ of $\mathrm{Hi}-\mathrm{Di}^{\mathrm{TM}}$ formamide (Applied Biosystems, USA) and $0.1 \mu \mathrm{l}$ of GeneScan ${ }^{\mathrm{TM}}-500 \mathrm{LIZ}^{\mathrm{TM}}$ size standard (Appilied Biosystems, USA) in a total volume of $11.1 \mu \mathrm{l}$. The microsatellite genotyping was performed using a Genetic Analyzer 3130xl (Applied Biosystems, USA) and the genotyping results were obtained using Genemapper (ver. 3.0, Applied Biosystems, USA).

\section{Statistical analysis}

The number of alleles, expected heterozygosity (He), observed heterozygosity (Ho) and polymorphic information content (PIC) and $F$-statistics were calculated for the selected 15 MS markers using the Cervus (ver 3.0) program (Marshall et al., 1998). Expected heterozygosity was derived from an unbiased formula (Nei, 1987) using allele frequencies assuming Hardy-Weinberg equilibrium which is a useful measure of informativeness of a locus. The polymorphism information content (PIC) is a closely related diversity measure which is estimated as:

$$
\overline{P I C_{l}}=1-\sum_{u=1}^{k} \tilde{p}_{l u}^{2}-\sum_{u=1}^{k-1} \sum_{v=u+1}^{k} 2 \tilde{p}_{l u}^{2} \tilde{p}_{l v}^{2}
$$

Here, $l$ denotes the $l$ th locus and $\mathrm{P}_{l u}$ and $\mathrm{P}_{l v}$ are the sample frequencies of a series of alleles $\mathrm{A}_{u}$ and $\mathrm{A}_{v}$ at the $l$ th locus (Botstein et al., 1980). F-statistics describe the amount of inbreeding-like effects within subpopulations $\left(F_{s t}\right)$, among subpopulations $\left(F_{i s}\right)$, and within the entire population $\left(F_{i t}\right)$ (Wright, 1965).

The expected probability of identity values among genotypes of random individuals (PI), random half sibs $\left(\mathrm{PI}_{\text {half-sibs }}\right)$ and random sibs $\left(\mathrm{PI}_{\text {sibs }}\right)$ were calculated using API-CALC (ver 1.0) (Ayres and Overall, 2004). This formula is only used for pairs of unrelated individuals such as relatives share genes, and consequently additional loci are likely to be required in order to adequately determine whether two profiles are from distinct individuals as follows:

$$
\mathrm{PI}_{\mathrm{ave}}=\sum_{i} P_{i}^{4}+\sum_{i} \sum_{j>i}\left(2 p_{i} p_{j}\right)_{2}
$$

Where, $\mathrm{p}_{i}$ and $\mathrm{p}_{j}$ are population allele proportions.

Also, genetic distance values were calculated among five native chicken lines using PowerMarker (Ver 3.25) 
(Liu and Muse, 2005). A phylogenetic tree was also population (Pritchard et al., 2000). constructed by Neighbor-Joining tree method (Nei, 1983) method embedded in PowerMarker software package. Finally, in Structure (Ver 2.3.3) program, we assumed five populations (i.e., $\mathrm{K}=5$ ) in these chicken lines to get the estimates of proportion of individual's ancestry from those

\section{RESULTS AND DISCUSSION}

Survival genetic diversity and differentiation

The highest values in the number of alleles, expected

Table 1. The investigated 150 MS markers for Korean native chicken lines. The numbers of alleles are indicated, and the selected 15 MS markers are in bold

\begin{tabular}{|c|c|c|c|c|c|c|c|c|c|c|c|c|c|c|}
\hline Marker & Chr. & $\begin{array}{c}\text { Map } \\
\text { position } \\
(\mathrm{cM})\end{array}$ & $\begin{array}{l}\text { No. of } \\
\text { allele }\end{array}$ & $\begin{array}{l}\text { Allele } \\
\text { Size } \\
\text { (bp) }\end{array}$ & Marker & Chr. & $\begin{array}{c}\text { Map } \\
\text { position } \\
(\mathrm{cM})\end{array}$ & $\begin{array}{l}\text { No. of } \\
\text { allele }\end{array}$ & $\begin{array}{c}\text { Allele } \\
\text { size(bp) }\end{array}$ & Marker & Chr. & $\begin{array}{c}\text { Map } \\
\text { position } \\
(\mathrm{cM})\end{array}$ & $\begin{array}{l}\text { No. of } \\
\text { allele }\end{array}$ & $\begin{array}{l}\text { Allele } \\
\text { size } \\
\text { (bp) }\end{array}$ \\
\hline MCW0248 & 1 & 21 & 3 & $215-223$ & MCW0016 & 3 & 247 & 5 & $134-146$ & GCT0016 & 9 & 41 & 8 & 108-154 \\
\hline ADL0160 & 1 & 33 & 2 & $113-133$ & GCT0053 & 3 & 263 & 5 & $128-154$ & ADL0191 & 9 & 44 & 6 & $128-150$ \\
\hline LEI0194 & 1 & 81 & 7 & $130-174$ & ADL0237 & 3 & 275 & 8 & $133-153$ & ADL0021 & 9 & 53 & 8 & 166-188 \\
\hline MCW0111 & 1 & 118 & 5 & $98-106$ & MCW0040 & 3 & 282 & 8 & $129-147$ & ADL0259 & 9 & 122 & 9 & $106-146$ \\
\hline ADL0188 & 1 & 133 & 6 & $145-165$ & LEI0166 & 3 & 300 & 3 & $346-356$ & MCW0134 & 9 & 132 & 7 & $260-284$ \\
\hline MCW0297 & 1 & 162 & 7 & 288-304 & MCW0037 & 3 & 317 & 3 & $152-156$ & MCW0228 & 10 & 0 & 6 & $221-239$ \\
\hline LEI0146 & 1 & 169 & 5 & $248-268$ & ADL0143 & 4 & 0 & 4 & $152-166$ & MCW0067 & 10 & 59 & 3 & $176-182$ \\
\hline MCW0106 & 1 & 94 & 3 & $125-131$ & ADL0255 & 4 & 3 & 4 & $97-109$ & ADL0158 & 10 & 101 & 4 & $188-204$ \\
\hline MCW0101 & 1 & 248 & 4 & $274-280$ & ADL0317 & 4 & 12 & 9 & $174-216$ & ADL0112 & 10 & 120 & 3 & $127-133$ \\
\hline ADL0268 & 1 & 288 & 5 & $105-117$ & ADL0203 & 4 & 35 & 7 & 168-194 & MCW0097 & 11 & 18 & 3 & $267-273$ \\
\hline LEI0108 & 1 & 300 & 10 & $256-310$ & MCW0295 & 4 & 75 & 5 & 88-100 & ADL0123 & 11 & 22 & 3 & $106-138$ \\
\hline LEI0169 & 1 & 400 & 5 & $232-248$ & ADL0241 & 4 & 80 & 7 & $201-215$ & MCW0332 & 12 & 90 & 2 & $196-200$ \\
\hline LEI0107 & 1 & 424 & 8 & 206-240 & ADL0246 & 4 & 112 & 9 & $146-164$ & ADL0147 & 13 & 32 & 4 & 211-217 \\
\hline MCW0145 & 1 & 455 & 7 & $182-210$ & ADL0194 & 4 & 118 & 4 & $198-214$ & LEI0251 & 13 & 47 & 12 & 98-132 \\
\hline MCW0020 & 1 & 460 & 4 & 183-189 & ROS0024 & 4 & 148 & 6 & $312-328$ & MCW0216 & 13 & 47 & 4 & $136-146$ \\
\hline LEI0134 & 1 & 527 & 6 & 291-311 & LEI0094 & 4 & 153 & 9 & $246-280$ & ADL0310 & 13 & 51 & 10 & $132-158$ \\
\hline MCW0107 & 1 & 565 & 4 & $110-118$ & MCW0098 & 4 & 217 & 2 & $260-262$ & ROS0083 & 13 & 55 & 7 & $109-129$ \\
\hline LEI0234 & 2 & 50 & 10 & $217-315$ & LEI0085 & 4 & 231 & 5 & $245-259$ & MCW0322 & 13 & 67 & 3 & $252-268$ \\
\hline MCW0131 & 2 & 102 & 6 & $196-216$ & MCW0263 & 5 & 28 & 4 & $227-249$ & MCW0104 & 13 & 74 & 11 & $188-226$ \\
\hline MCW0206 & 2 & 104 & 5 & $226-240$ & MCW0193 & 5 & 50 & 9 & 298-318 & ADL0200 & 14 & 16 & 7 & $112-138$ \\
\hline ADL0176 & 2 & 116 & 5 & $184-200$ & ROS0013 & 5 & 79 & 8 & $220-236$ & LEI0098 & 14 & 37 & 6 & $150-170$ \\
\hline MCW0063 & 2 & 119 & 8 & 132-150 & ADL0292 & 5 & 83 & 7 & $112-138$ & MCW0123 & 14 & 45 & 5 & $80-90$ \\
\hline ADL0217 & 2 & 121 & 4 & $150-156$ & MCW0214 & 5 & 88 & 10 & 268-302 & MCW0080 & 15 & 49 & 4 & $270-280$ \\
\hline MCW0065 & 2 & 142 & 6 & $98-122$ & MCW0078 & 5 & 93 & 3 & $135-143$ & ADL0293 & 17 & 26 & 7 & $105-119$ \\
\hline LEI0089 & 2 & 165 & 6 & $182-200$ & LEI0145 & 5 & 98 & 11 & $303-333$ & MCW0330 & 17 & 41 & 4 & $254-286$ \\
\hline MCW0039 & 2 & 202 & 5 & $128-142$ & MCW0223 & 5 & 123 & 4 & $177-195$ & MCW0151 & 17 & 57 & 6 & $250-266$ \\
\hline MCW0034 & 2 & 233 & 7 & $217-237$ & MCW0029 & 5 & 128 & 11 & $137-187$ & ADL0304 & 18 & 7 & 8 & $127-161$ \\
\hline LEI0096 & 2 & 233 & 6 & $216-240$ & MCW0081 & 5 & 151 & 2 & $113-131$ & MCW0219 & 18 & 47 & 4 & $224-240$ \\
\hline ADL0181 & 2 & 241 & 3 & $175-179$ & ADL0166 & 5 & 162 & 9 & $124-162$ & MCW0266 & 19 & 0 & 3 & $163-175$ \\
\hline MCW0173 & 2 & 243 & 12 & $230-272$ & ADL0298 & 5 & 198 & 6 & $105-121$ & MCW0119 & 20 & 0 & 7 & $102-142$ \\
\hline MCW0087 & 2 & 252 & 9 & $267-287$ & MCW0014 & 6 & 50 & 4 & $173-187$ & ADL0324 & 20 & 18 & 6 & $157-181$ \\
\hline MCW0009 & 2 & 261 & 2 & $162-172$ & MCW0250 & 6 & 59 & 5 & $226-240$ & ADL0034 & 20 & 26 & 6 & $111-121$ \\
\hline MCW0137 & 2 & 273 & 7 & $240-264$ & ADL0230 & 6 & 63 & 6 & $105-115$ & SLC2A1 & 21 & 71.04 & 2 & 293-295 \\
\hline MCW0288 & 2 & 275 & 5 & $108-118$ & ADL0159 & 6 & 67 & 10 & $78-126$ & ADL0262 & 23 & 0 & 3 & 105-109 \\
\hline LEI0070 & 2 & 379 & 11 & $177-213$ & MCW0120 & 7 & 44 & 10 & $258-286$ & MCW0165 & 23 & 1 & 3 & $114-118$ \\
\hline ROS0074 & 2 & 302 & 3 & $315-321$ & MCW0201 & 7 & 79 & 4 & 299-309 & ADL0289 & 23 & 7 & 3 & $173-177$ \\
\hline MCW0264 & 2 & 320 & 6 & 224-240 & MCW0183 & 7 & 86 & 3 & 291-319 & MCW0301 & 24 & 48 & 6 & $264-292$ \\
\hline GCT0002 & 2 & 349 & 5 & $154-172$ & ADL0279 & 7 & 92 & 8 & $87-115$ & MCW0285 & 26 & 38 & 7 & $179-195$ \\
\hline MCW0282 & 2 & 378 & 5 & $286-310$ & ROS0019 & 7 & 101 & 10 & $119-147$ & MCW0069 & 26 & 47 & 7 & $155-173$ \\
\hline LEI0141 & 2 & 382 & 8 & $220-242$ & MCW0236 & 7 & 109 & 6 & $306-328$ & LEI0074 & 26 & 67 & 6 & $224-240$ \\
\hline MCW0157 & 2 & 474 & 6 & $285-297$ & MCW0316 & 7 & 127 & 2 & $158-186$ & MCW0300 & 27 & 11 & 3 & $122-130$ \\
\hline MCW0261 & 3 & $\mathbf{0}$ & 8 & $225-251$ & ADL0315 & 7 & 140 & 2 & $245-247$ & ROS0073 & 22 & 0 & 4 & $280-292$ \\
\hline MCW0083 & 3 & 51 & 5 & $78-86$ & MCW0275 & 8 & 6 & 3 & $128-150$ & LEI0135 & 28 & 0 & 6 & $132-142$ \\
\hline MCW0222 & 3 & 85 & 4 & $217-223$ & ROS0026 & 8 & 14 & 6 & $109-119$ & ROS0249 & 32 & 20 & 4 & $148-162$ \\
\hline MCW0212 & 3 & 154 & 3 & $192-206$ & MCW0095 & 8 & 26 & 5 & $72-82$ & ADL0273 & $\mathrm{Z}$ & 73 & 4 & $144-168$ \\
\hline ADL0248 & 3 & 164 & 7 & $122-158$ & MCW0160 & 8 & 35 & 5 & $205-229$ & ADL0201 & $\mathrm{Z}$ & 87 & 4 & $138-144$ \\
\hline MCW0127 & 3 & 167 & 8 & $227-247$ & ADL0154 & 8 & 46 & 8 & $125-171$ & MCW0154 & $\mathrm{Z}$ & 95 & 3 & $170-186$ \\
\hline MCW0103 & 3 & 201 & 2 & $267-271$ & ADL0278 & 8 & 94 & 4 & 111-119 & LEI0144 & $\mathrm{Z}$ & 131 & 4 & $251-269$ \\
\hline MCW0224 & 3 & 218 & 4 & $292-300$ & MCW0351 & 8 & 105 & 5 & $149-159$ & LEI0121 & $\mathrm{Z}$ & 131 & 3 & $257-273$ \\
\hline MCW0126 & 3 & 231 & 3 & $112-132$ & ROS0078 & 9 & 0 & 16 & $172-246$ & LEI0075 & $\mathrm{Z}$ & 165 & 8 & $164-200$ \\
\hline
\end{tabular}


Table 2. Primer information for 15 selected microsatellite markers

\begin{tabular}{lccll}
\hline marker & Chr & Dye & \multicolumn{1}{c}{ Forward $\left(5^{\prime}-3^{\prime}\right)$} & \multicolumn{1}{c}{ Reverse $\left(5^{\prime}-3^{\prime}\right)$} \\
\hline LEI0107 & 1 & NED & GCTGCTCAGAAGCATCTGTGC & ATCATTGCTACACCATGGTTC \\
MCW0145 & 1 & FAM & ACTTTATTCTCCAAATTTGGCT & AAACACAATGGCAACGGAAAC \\
MCW0063 & 2 & FAM & GGCTCCAAAAGCTTGTTCTTAGCT & GAAAACCAGTAAAGCTTCTTAC \\
MCW0087 & 2 & NED & ATTTCTGCAGCCAACTTGGAG & CTCAGGCAGTTCTCAAGAACA \\
MCW0264 & 2 & FAM & CTTACTTTTCACGACAGAAGC & AGACTGAGTCACACTCGTAAG \\
MCW0261 & 3 & FAM & GAGCAGTTCATATGAAGTGCAG & GTAGTAGCAGCTACACCAGAG \\
ADL0292 & 5 & FAM & CCAAATCAGGCAAAACTTCT & AAATGGCCTAAGGATGAGGA \\
MCW0029 & 5 & VIC & GTGGACACCCATTTGTACCCTATG & CATGCAATTCAGGACCGTGCA \\
ADL0021 & 9 & PET & GCTCCTCGCTTTGCTCTGAA & GCTTAGCCTCATCTCTTGTA \\
ADL0259 & 9 & VIC & CTCATTGCAGAGGAAGTTCT & GTAATGGAGGATGCTCAGGT \\
GCT0016 & 9 & NED & TCCAAGGTTCTCCAGTTC & GGCATAAGGATAGCAACAG \\
LEI0251 & 13 & NED & GATCTAGAAATGGCTGACTGAC & GGGTTACTCTTATGTTTAATGATGTC \\
MCW0104 & 13 & FAM & TAGCACAACTCAAGCTGTGAG & AGACTTGCACAGCTGTGTACC \\
ADL0304 & 18 & FAM & GGGGAGGAACTCTGGAAATG & CCTCATGCTTCGTGCTTTTT \\
ADL0324 & 20 & NED & TTGCCTCGACGGACCACAAT & GCAGCCCCGCCAAGTAACTG \\
\hline
\end{tabular}

heterozygosity (He), observed heterozygosity (Ho) and polymorphism information content (PIC) are the vital index for the selection of markers in chicken line discrimination. In this study, we selected 15 microsatellite markers out of the $150 \mathrm{MS}$ markers for the discrimination of Korean native chicken lines. The heterozygosity ( $\mathrm{He}$ and $\mathrm{Ho}$ ) and polymorphic information content (PIC) value for the Korean native chicken lines are summarized in Table 3. Among these selected 15 MS markers, LEI0251 is contained highest value of the number of allele, He, Ho and PIC for $12,0.882,0.852$ and 0.865 , respectively. While, MCW0264 marker is showed lowest He and PIC value of 0.709 and 0.648 , respectively, but the Ho value lowest in GCT0016 marker. The selection process of MS markers were evaluated for the genetic diversity as of the number of alleles, He, Ho and PIC values range of 6 to $12,0.709$ to $0.882,0.466$ to 0.852 and 0.648 to 0.865 , respectively. In order to investigate genetic relationships and breed differentiation, highly polymorphic MS markers were selected. Estimation of genotypic diversity of heterozygosity and PIC value informativeness of MS markers were previously used for the determining the animal breed selection (Berthouly et al., 2008). For the animal traceability, $\mathrm{PIC}>0.5$ and $\mathrm{He}>0.6$ are the most reasonable informative locus for application in genetics (Botstein et al., 1980). In this study, selected $15 \mathrm{MS}$ markers were highly informative among the five chicken lines and these MS markers are appropriate for

Table 3. The statistical analysis of heterozygosity (He and $\mathrm{H}_{\mathrm{O}}$ ), polymorphism information content (PIC), and $F$-statistics value using selected 15 microsatellite markers among the native chicken lines

\begin{tabular}{lccllllll}
\hline Locus & Chr & No. of allele & He & Ho & PIC & Fst & Fit & Fis \\
\hline LEI0107 & 1 & 8 & 0.77 & 0.716 & 0.739 & 0.1076 & 0.1001 & -0.0083 \\
MCW0145 & 1 & 7 & 0.791 & 0.727 & 0.759 & 0.1141 & 0.0774 & -0.0413 \\
MCW0063 & 2 & 8 & 0.712 & 0.648 & 0.665 & 0.0956 & 0.1142 & 0.0206 \\
MCW0087 & 2 & 9 & 0.83 & 0.761 & 0.806 & 0.1219 & 0.1074 & -0.0165 \\
MCW0264 & 2 & 6 & 0.709 & 0.713 & 0.648 & 0.0309 & 0.0013 & -0.0306 \\
MCW0261 & 3 & 8 & 0.842 & 0.83 & 0.817 & 0.1324 & 0.0455 & -0.1002 \\
ADL0292 & 5 & 7 & 0.821 & 0.716 & 0.791 & 0.1345 & 0.1610 & 0.0306 \\
MCW0029 & 5 & 11 & 0.789 & 0.739 & 0.77 & 0.1215 & 0.0761 & -0.0517 \\
ADL0021 & 9 & 8 & 0.849 & 0.795 & 0.825 & 0.1111 & 0.0892 & -0.0246 \\
ADL0259 & 9 & 9 & 0.846 & 0.773 & 0.826 & 0.0890 & 0.0923 & 0.0036 \\
GCT0016 & 9 & 8 & 0.804 & 0.466 & 0.773 & 0.2473 & 0.4513 & 0.2710 \\
LEI0251 & 13 & 12 & 0.882 & 0.852 & 0.865 & 0.0927 & 0.0538 & -0.0429 \\
MCW0104 & 13 & 11 & 0.846 & 0.659 & 0.823 & 0.1965 & 0.2349 & 0.0478 \\
ADL0304 & 18 & 8 & 0.768 & 0.678 & 0.735 & 0.1004 & 0.1449 & 0.0495 \\
ADL0324 & 20 & 6 & 0.767 & 0.568 & 0.723 & 0.2174 & 0.2853 & 0.0868 \\
Total/Mean & 8 & $126 / 8.4$ & 0.802 & 0.709 & 0.771 & 0.1290 & 0.1370 & 0.0093 \\
\hline
\end{tabular}

$\mathrm{He}=$ Expected heterozygosity, $\mathrm{Ho}=$ Observed heterozygosity, $\mathrm{PIC}=$ Polymorphism information content, Fit $=$ Total inbreeding, Fst $=$ Genetic distance, Fis $=$ Within inbreeding. 
Table 4. Pair-wise genetic distance among five chicken lines

\begin{tabular}{lcccc}
\hline & KNC_B & KNC_G & KNC_R & KNC_W \\
\hline KNC_G & 0.156 & - & - & - \\
KNC_R & 0.103 & 0.164 & - & - \\
KNC_W & 0.171 & 0.137 & 0.137 & - \\
KNC_Y & 0.083 & 0.107 & 0.111 & 0.107 \\
\hline
\end{tabular}

discrimination as well.

$F$-statistics (Wright, 1965) were estimated in a fixation index as genetic differentiation (Fst), the global heterozygote deficit among five chicken lines (Fit) and the heterozygote deficit within line (Fis) among the $15 \mathrm{MS}$ markers (Table 3). Among these markers, estimation of fixation index has been discovered for Fst, Fit and Fis values ranging from 0.0309 to $0.2473,0.0013$ to 0.4513 and -0.1002 to 0.271 , respectively. The estimated mean value of the total inbreeding (Fit), within line inbreeding (Fis) and genetic distance were $0.137,0.0093$ and 0.129 , respectively. The high $F$-statistics value was contained in GCT0016 marker of $0.2473,0.4513$ and 0.271 for Fst, Fit and Fis, respectively. While, the lowest value for genetic distance (Fst) and total inbreeding (Fit) was 0.0309 and 0.0013 , respectively, and lowest within inbreeding value of -0.1002 in MCW0261 marker. In addition, pair wise co-ancestry matrix genetic distance was confirmed 0.083 to 0.171 among Korean native chicken lines (Table 4). The highest genetic distance was obtained between KNC_B and KNC_W (17.1\%), while the lowest genetic distance was observed between KNC_B and $\mathrm{KNC}_{-} \mathrm{Y}(8.3 \%)$.

The expected probability of identity values of $15 \mathrm{MS}$ markers were calculated in random individuals (PI), random half-sib $\left(\mathrm{PI}_{\text {half-sibs }}\right)$ and random sibs $\left(\mathrm{PI}_{\text {sibs }}\right)$, which were estimated as $7.98 \times 10^{-29}, 2.88 \times 10^{-20}$ and $1.25 \times 10^{-08}$, respectively (Table 5). Also, acceptance of marker accuracy for discrimination power was evaluated (Figure 1). The expected probability of chicken lines identity among the genotypes of random individuals (PI), random half-sib $\left(\mathrm{PI}_{\text {half-sibs }}\right)$ and random sibs $\left(\mathrm{PI}_{\text {sibs }}\right)$ were suggested approximately 12 markers. Thus, the expected probability of identity values from $12 \mathrm{MS}$ markers in random individuals $(\mathrm{PI})$, random half-sib $\left(\mathrm{PI}_{\text {half-sibs }}\right)$ and random sibs $\left(\mathrm{PI}_{\text {sibs }}\right)$ were estimated as $1.01 \times 10^{-20}, 3.85 \times 10^{-15}$ and
Table 5. The expected probability values among genotypes of random individuals $(\mathrm{PI})$, random half-sib $\left(\mathrm{PI}_{\text {half-sibs }}\right)$, random sibs $\left(\mathrm{PI}_{\text {sibs }}\right)$ and total expected probability (PE) for discrimination chicken lines using 12 and 15 markers

\begin{tabular}{lcccc}
\hline No. of marker & PI & $\mathrm{PI}_{\text {half-sibs }}$ & $\mathrm{PI}_{\text {sibs }}$ & $\mathrm{PE}$ \\
\hline 15 & $7.98 \times 10^{-29}$ & $2.28 \times 10^{-20}$ & $1.25 \times 10^{-8}$ & 0.999858 \\
12 & $1.01 \times 10^{-20}$ & $3.85 \times 10^{-15}$ & $1.69 \times 10^{-7}$ & 0.999555 \\
\hline
\end{tabular}

$1.69 \times 10^{-7}$, respectively. Overall, the total expected probability of identity values was $99.9 \%$ for the discrimination of Korean native chicken. Our study identified markers in Korean native chicken lines which are applicable to future breeding plans, as well as discrimination markers for these lines.

\section{Phylogenetic and structure analysis}

The unrooted phylogenetic neighbor-joining (NJ) tree was constructed using 15 MS markers that clearly differentiated among five native chicken lines (Figure 2). Based on the equation of Nei et al. (1983), a phylogenetic tree has been estimated by the distribution of allele sharing with genetic distance $(F s t)$. In our analysis, the $\mathrm{KNC}_{-} \mathrm{W}$ line is different from the $\mathrm{KNC} \_\mathrm{B}$ and $\mathrm{KNC} \_\mathrm{R}$ lines. Also, the $\mathrm{KNC}_{-} \mathrm{G}$ line shows a long genetic distance from KNC_R. However, the $\mathrm{KNC}_{-} \mathrm{Y}$ line is very close to the KNC_W and KNC_R lines. The dendrogram drawn from the genetic distance matrix using 15 MS markers can also be used for the conservation of Korean native chicken lines. Also, five different lines in Korean native chickens were well discriminated by using these 15 MS markers.

In 1994, the conservation policy for the development of Korean native chicken lines was launched. As a result, five breeds with nine chicken lines were documented. In order to investigate the genetic structure of the five Korean native chicken lines, a structured program of genetic analysis was applied (Figure 3). Based on the line specific clusters, chicken line structure was estimated with a $\mathrm{K}$ value of 5 . The estimated average individual cluster value in the specific line was accurate to more than $95 \%$ (data was not shown). Our structure result for the five Korean native chicken lines indicates around 5\% genetic admixture with other lines. In conclusion, our study shows the genetic
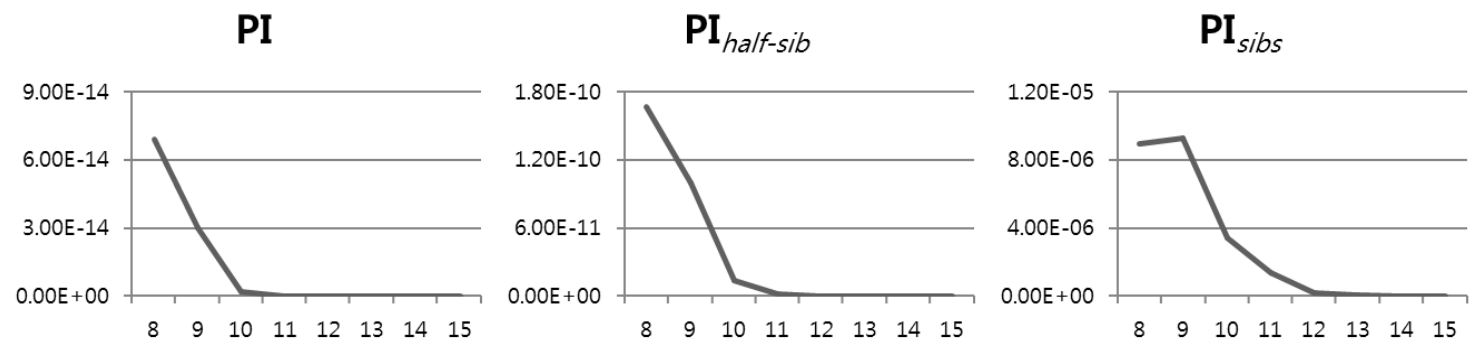

Figure 1. The expected probability of identity values among genotypes of random individuals (PI), random half-sib (PI $\left.{ }_{h a l f-s i b s}\right)$ and random sibs $\left(\mathrm{PI}_{\text {sibs }}\right)$ were suggested markers for discrimination of chicken lines. 


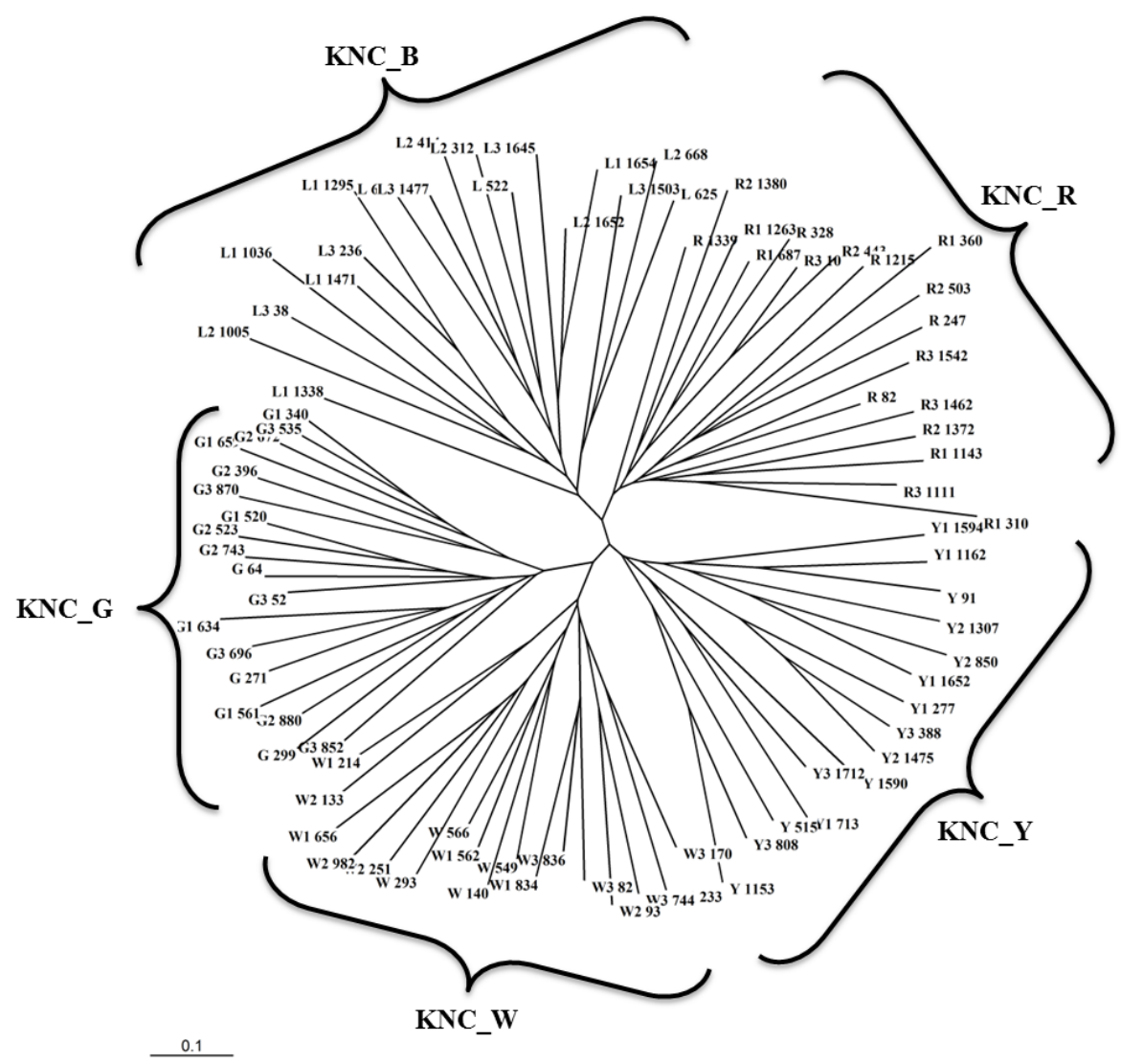

Figure 2. Construction of unrooted phylogenetic neighbor-joining (NJ) tree among the five chicken lines using 15 selected MS markers.

diversity, genetic distance, and population structure among five Korean native chicken lines, using 15 selected MS markers. The maintaining of Korean native chickens with appropriate discrimination markers is the essential for conservation of this breed. Our results indicated that these MS markers will be used to aid the conservation, traceability and future improvement of Korean native chicken lines.

\section{ACKNOWLEDGEMENTS}

This work was supported by a grant from the NextGeneration BioGreen 21 Program (No. PJ008133), Rural Development Administration, Korea.

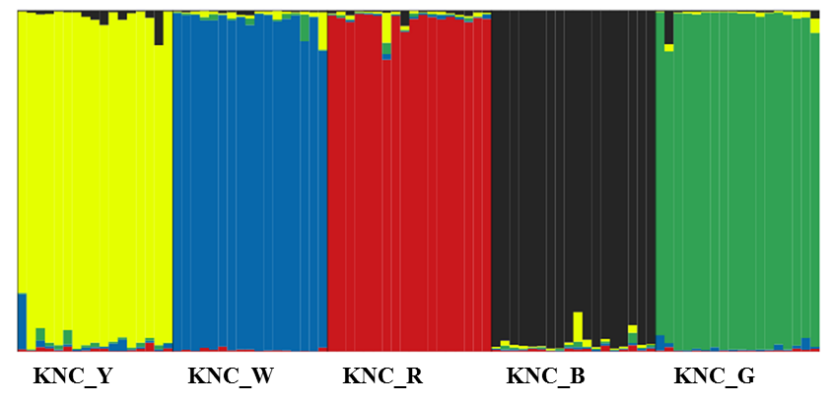

Figure 3. Construction of genetic structure using individual cluster ( $\mathrm{K}$ value of 5 ) among the chicken lines.

\section{REFERENCES}

Almasy, L. and J. Blangero. 2009. Human QTL linkage mapping. Genetica. 136:333-340.

Berthouly, C., B. Bed'Hom, M. Tixier-Boichard, C. F. Chen, Y. P. Lee, D. Laloe, H. Legros, E. Verrier and X. Rognon. 2008. Using molecular markers and multivariate methods to study the genetic diversity of local european and asian chicken breeds. Anim. Genet. 39:121-129.

Blott, S. C., J. L. Williams and C. S. Haley. 1999. Discriminating among cattle breeds using genetic markers. Heredity. 82:613619.

Bodzsar, N., H. Eding, T. Revay, A. Hidas and S. Weigend. 2009. Genetic diversity of hungarian indigenous chicken breeds based on microsatellite markers. Anim. Genet. 40:516-523.

Botstein, D., R. L. White, M. Skolnik and R. W. Davis. 1980. Construction of a genetic linkage map in man using restriction fragment length polymorphisms. Am. J. Hum. Genet. 32:314331.

Cheng, H. H. and L. B. Crittenden. 1994. Microsatellite markers for genetic-mapping in the chicken. Poult. Sci. 73:539-546.

Dalvit, C., M. DeMarchi and M. Cassandro. 2007. Genetic traceability of livestock products: A review. Meat Sci. 77:437449.

Ding, F. X., G. X. Zhang, J. Y. Wang, Y. Li, L. J. Zhang, Y. Wei, H. H. Wang, L. Zhang and Q. R. Hou. 2010. Genetic diversity of a Chinese native chicken breed, Bian chicken, based on twenty-nine microsatellite markers. Asian-Aust. J. Anim. Sci. 
23:154-161.

FAO. 2007. Status of animal genetic resources. In: The state of the world's animal genetic resources for food and agriculture (Ed. B. Rischkowsky and D. Pilling). Commission on Genetic Resources for Food and Agriculture, Rome, Italy. pp. 23-49.

Hillel, J., M. A. Groenen, M. Tixier-Boichard, A. B. Korol, L. David, V. M. Kirzhner, T. Burke, A. B. Dirie, R. P. A. Crooijmans, K. Elo, M. W. Feldman, P. J. Freidlin, A. MakiTanila, M. Oortwijn, P. Thomson, A. Vignal, K. Wimmers and S. Weigend. 2003. Biodiversity of 52 chicken populations assessed by microsatellite typing of DNA pools. Genet. Sel. Evol. 35:533-557.

Hoque, M. R., K. C. Jung, B. K. Park, K. D. Choi and J. H. Lee. 2009. Genetic variability of mtDNA D-loop region in Korean native chickens. Korean J. Poult. Sci. 36:323-328.

Hoque, M. R., S. H. Lee, K. C. Jung, B. S. Kang, M. N. Park, H. K. Lim, K. D. Choi and J. H. Lee. 2011. Discrimination of Korean native chicken populations using SNPs from mtDNA and MHC polymorphisms. Asian-Aust. J. Anim. Sci. 24:16371643.

Jacobsson, L., H. B. Park, P. Wahlberg, S. Jiang, P. B. Siegel and L. Andersson. 2004. Assignment of fourteen microsatellite markers to the chicken linkage map. Poult. Sci. 83:1825-1831.

Kaya, M. and M. A. Yildiz. 2008. Genetic diversity among turkish native chickens, denizli and gerze, estimated by microsatellite markers. Biochem. Genet. 46:480-491.

Kong, H. S., J. D. Oh, J. H. Lee, K. J. Jo, B. D. Sang, C. H. Choi, S. D. Kim, S. J. Lee, S. H. Yeon, G. J. Jeon and H. K. Lee. 2006. Genetic variation and relationships of Korean native chickens and foreign breeds using 15 microsatellite markers. Asian-Aust. J. Anim. Sci. 19:1546-1550.

Liu, K. and S. V. Muse. 2005. Powermarker: An integrated analysis environment for genetic marker analysis. Bioinformatics. 21:2128-2129.

Marshall, T. C., J. Slate, L. E. Kruuk and J. M. Pemberton. 1998. Statistical confidence for likelihood-based paternity inference in natural populations. Mol. Ecol. 7:639-655.
Miller, S. A., D. D. Dykes and H. F. Polesky. 1988. A simple salting out procedure for extracting DNA from human nucleated cells. Nucleic Acids Res. 16:1215.

Muchadeyi, F. C., H. Eding, C. B. Wollny, E. Groeneveld, S. M. Makuza, R. Shamseldin, H. Simianer and S. Weigend. 2007. Absence of population substructuring in zimbabwe chicken ecotypes inferred using microsatellite analysis. Anim. Genet. 38:332-339.

MIFAFF. 2009. Primary statistics of Food, Agriculture, Forestry and Fisheries, Korea.

Mwacharo, J. M., K. Nomura, H. Hanada, H. Jianlin, O. Hanotte and T. Amano. 2007. Genetic relationships among kenyan and other east african indigenous chickens. Anim. Genet. 38:485490.

Nei, M. 1987. Molecular evolutionary genetics. Columbia University Press, New York.

Nei, M., F. Tajima and Y. Tateno. 1983. Accuracy of estimated phylogenetic trees from molecular data. J. Mol. Evol. 19:153170.

Pritchard, J. K., M. Stephens and P. Donnelly. 2000. Inference of population structure using multilocus genotype data. Genetics. 155:945-959.

Tadano, R., M. Nishibori, Y. Imamura, M. Matsuzaki, K. Kinoshita, M. Mizutani, T. Namikawa and M. Tsudzuki. 2008. High genetic divergence in miniature breeds of japanese native chickens compared to red junglefowl, as revealed by microsatellite analysis. Anim. Genet. 39:71-78.

Tadano, R., M. Nishibori, N. Nagasaka and M. Tsudzuki. 2007a. Assessing genetic diversity and population structure for commercial chicken lines based on forty microsatellite analyses. Poult. Sci. 86:2301-2308.

Tadano, R., M. Sekino, M. Nishibori and M. Tsudzuki. 2007b. Microsatellite marker analysis for the genetic relationships among japanese long-tailed chicken breeds. Poult. Sci. 86:460469.

Wright, S. 1965. The interpretation of population structure by fstatistics with special regard to systems of mating. Evol. 19:395-420. 